\title{
Trends in treatment for patients with depression in general practice in Norway, 2009-2015: nationwide registry-based cohort study (The Norwegian GP-DEP Study)
}

Sabine Ruths ${ }^{1,2^{*}}$, Inger Haukenes ${ }^{1,2}$, Øystein Hetlevik ${ }^{1,2}$, Tone Smith-Sivertsen ${ }^{1,3}$, Stefan Hjørleifsson ${ }^{1,2}$, Anneli B Hansen ${ }^{1,2}$, Sharline Riiser ${ }^{1,2}$, Heidi Marie Meling ${ }^{1,2}$ and Valborg Baste ${ }^{1}$

\begin{abstract}
Background: Depression is highly prevalent, but knowledge is scarce as to whether increased public awareness and strengthened government focus on mental health have changed how general practitioners (GPS) help their depressed patients. This study aimed to examine national time trends in GP depression care and whether trends varied regarding patient gender, age, and comorbidity.

Methods: Nationwide registry-based cohort study, Norway. The study population comprised all residents aged 20 years or older with new depression diagnoses recorded in general practice, 2009-2015. We linked reimbursement claims data from all consultations in general practice for depression with information on demographics and antidepressant medication. The outcome was type(s) of GP depression care during 12 months from the date of diagnosis: (long) consultation, talking therapy, antidepressant drug treatment, sickness absence certification, and referral to secondary mental health care. Covariates were patient gender, age, and comorbidity. The data are presented as frequencies and tested with generalized linear models.

Results: We included 365,947 new depression diagnoses. Mean patient age was 44 years (SD =16), 61.9\% were women, $41.2 \%$ had comorbidity. From 2009 to 2015, proportions of patients receiving talking therapy (42.3-63.4\%), long consultations (56.4-71.8\%), and referral to secondary care (16.6-21.6\%) increased, while those receiving drug treatment (31.3-25.9\%) and sick-listing (58.1-50\%) decreased. The trends were different for gender (women had a greater increase in talking therapy and a smaller decrease in sick-listing, compared to men), age (working-aged patients had a smaller increase in talking therapy, a greater increase in long consultations, and a smaller decrease in antidepressant drug use, compared to older patients) and comorbidity (patients with mental comorbidity had a smaller increase in talking therapy and a greater increase in long consultations, compared to those with no comorbidity and somatic comorbidity).
\end{abstract}

\footnotetext{
* Correspondence: saru@norceresearch.no

'Research Unit for General Practice, NORCE Norwegian Research Centre, Årstadveien 17, N-5009 Bergen, Norway

${ }^{2}$ Department of Global Public Health and Primary Care, University of Bergen, Bergen, Norway

Full list of author information is available at the end of the article
}

C C The Author(s). 2021 Open Access This article is licensed under a Creative Commons Attribution 4.0 International License, which permits use, sharing, adaptation, distribution and reproduction in any medium or format, as long as you give appropriate credit to the original author(s) and the source, provide a link to the Creative Commons licence, and indicate if changes were made. The images or other third party material in this article are included in the article's Creative Commons licence, unless indicated otherwise in a credit line to the material. If material is not included in the article's Creative Commons licence and your intended use is not permitted by statutory regulation or exceeds the permitted use, you will need to obtain permission directly from the copyright holder. To view a copy of this licence, visit http://creativecommons.org/licenses/by/4.0/ The Creative Commons Public Domain Dedication waiver (http://creativecommons.org/publicdomain/zero/1.0/) applies to the data made available in this article, unless otherwise stated in a credit line to the data. 
Conclusions: The observed time trends in GP depression care towards increased provision of psychological treatment and less drug treatment and sick-listing were in the desired direction according to Norwegian health care policy. However, the large and persistent differences in treatment rates between working-aged and older patients needs further investigation.

Keywords: Depression, General practice, Mental health, Drug therapy, Psychotherapy, Secondary care, Sick leave, Health services research, Large database research

\section{Background}

Depression is among the three leading causes of years lived with disability (YLD) globally, at great personal and societal costs [1]. The ECNP/EBC Report estimated a one-year prevalence of major depression at $6.9 \%$, equivalent to 30.3 million people in Europe [2]. Women [3], older adults $[4,5]$, and people with multimorbidity $[6,7]$ are particularly at risk. A review of European community studies estimated that only $26 \%$ of people with a mental disorder had sought health care, suggesting a considerable degree of unmet needs [8].

The World Health Organization (WHO) has recommended integrating mental health care into existing care settings to increase availability [9]. General practitioners (GPs) are usually the first encounter depressed people have with the health service, thus playing a crucial role in diagnosing and treating depression $[10,11]$. In Norway, several government policies have been implemented that may change the provision of depression care in general practice. First, the National Program for Mental Health was implemented from 1999 to 2006 [12], mandating efforts to expand service capacity and quality in community-based and specialist mental health services for adults. The program resulted in a significant capacity shift from psychiatric beds to outpatient services [13]. With respect to primary care, low-threshold mental health services were established in the local communities, such as Healthy Life Centers, psychologists, outreach teams, and urgent mental health care. Second, a national guideline for diagnosing and treating adults with depression in primary and secondary care was published in 2009 [14]. While the use of antidepressant medication has increased dramatically during the 1990s $[15,16]$, the Norwegian and UK guidelines emphasize, e.g., the evidence base for drug treatment $[14,17]$. Third, economic incentives are currently channeled into the field to stimulate GPs to give more priority to providing mental health care to their patients, e.g., talking therapy. Finally, policymakers have addressed the positive mental health effects of work participation, urging GPs to limit sick leave certification for patients with mild mental disorders [18]. Until now, however, little research has been conducted to ascertain whether and how GP depression care delivery has changed during the times of these policy changes.
The treatment of depression mainly consists of psychological and/or pharmacological interventions [19]. In moderate to severe cases, GPs can refer patients to secondary mental care provided by psychologists or psychiatrists. In some countries, including Norway, Sweden and the UK, GPs have an additional key role in certifying sick leave for patients with reduced work capacity [20]. Recent studies of GP depression care provided in the Netherlands and the UK indicate trends towards less prescription of antidepressant medication [21, 22]. However, time trends in GP depression care in Norway are poorly documented.

Based on information on all GP encounters and treatments stored in national databases, we examined the trends in treatment for depression in Norwegian general practice from 2009 to 2015. Further, we investigated whether trends varied across patient gender, age, and comorbidity.

\section{Methods}

All residents in Norway have access to the public health services and prescription drugs (for example antidepressant drugs), covered by the National Insurance Scheme. A patient list-system was introduced in 2001, entitling all residents to have a regular GP [23]. The GPs provide comprehensive care for a broad range of health issues, and act as gatekeepers to secondary health care and social security benefits [24].

\section{Design}

We conducted a nationwide registry-based cohort study comprising all individuals with one or more new depression diagnoses recorded in general practice during 2009-2015. We examined the provision of GP depression care for 12 months from the date of the depression diagnosis (index date).

\section{Data sources}

Information drawn from national registries for the period 2008 through 2016 was linked at the individual patient level and GP level, using the (encrypted) unique personal identification number assigned to all residents of Norway. Data was stored and analyzed in a safe server at the University of Bergen. 
The study population was drawn from the Population Registry. We obtained complete information regarding gender, year of birth, death, and emigration for all citizens born before 1989. The Control and Reimbursement of Health Care Claims (KUHR) database stores data on all fee-for-service claims from public primary care providers. For each encounter with a GP, we extracted information on date of contact, reimbursement code(s) for diagnostic and therapeutic measures, and one or more diagnoses according to the International Classification of Primary Care 2nd version (ICPC-2), as recorded by the GPs. The Norwegian Prescription Database (NorPD) contains information on all prescription drugs dispensed at pharmacies to individual patients treated in ambulatory care. For each prescription of a depression drug, NorPD provided information on date of dispensing, generic drug information (Anatomical Therapeutic Chemical (ATC) code), and any reimbursement code linked to specific diagnoses. NorPD lacks information at the individual level on medication dispensed to people staying in hospitals or nursing homes. The Norwegian Patient Registry (NPR) comprises information on all patient contacts with refundable secondary health care. We obtained information on date of depression contact with secondary care providers, with diagnoses according to the International Classification of Disease 10th revision (ICD-10). The data extracts provided by the national registries contained no missing information.

\section{Study population}

The source population at risk comprised all residents of Norway born before 01.01.1996 and alive 01.01.2009 (4, 017,989 individuals). First, we identified all individuals with one or more depression diagnoses recorded in general practice (GP-consultation with the ICPC-2 code P76 Depression in KUHR) during each year 2008-2015). Second, to establish a cohort of patients with new depression diagnoses, washout during 12 months prior to index date was performed for patients with a depression diagnosis in general practice (P76 in KUHR) or secondary health care (ICD-10 codes F32, F33, F34 or F41.2 in NPR), and/or dispensed antidepressant medication (NorPD). The 12-month contact-free interval was defined according to the algorithm published by Nielen and coworkers [25]. We thus identified 307,237 unique patients with new diagnoses of depression. Out of these, 51,753 incurred two or more depression episodes that were at least 12 months apart.

\section{Outcome}

Information on GP depression care linked to ICPC-2 code P76 Depression, received during 12 months from the index date, was included from KUHR. We subsequently counted the number of GP consultations during one year from the index date. Types of depression care studied were consultations, including long consultations (i.e., > $20 \mathrm{~min}$ ), talking therapy, referral to secondary mental health care, and certification of sickness absence. Throughout this paper, we use the term 'talking therapy' for GPs' psychological treatment, including supportive talk, counseling, and structured psychotherapeutic methods such as cognitive-behavioral therapy [26-28]. Until July 2011, GPs could use the reimbursement code for talking therapy only if the patient had been referred to specialist mental health care, and until July 2014, this code could not be combined with the higher rewarding reimbursement code for long consultation. Considering that the latter change may have influenced how GPs use these reimbursement codes, we also provide combined figures. The variables were binary (yes, no). In addition, each variable had information on whether care started at the index consultation or if it started during follow-up. We investigated certification of sickness absence among patients between 20 and 66 years of age (at index date). From NorPD, we included all antidepressant drugs (ATC code N06A) reimbursed by the Norwegian State for the treatment of depression, dispensed during 12 months from the index date (yes, no).

\section{Covariates}

Gender (women, men). We recoded patient age into two groups, 20-66 years (working-aged) and $67+$ years. Preexisting comorbidity was categorized as no pre-existing comorbidity, somatic only, mental only, or both somatic and mental health condition(s) [6].

\section{Statistical analysis}

The annual incidence of patients recorded with a new depression diagnosis in general practice was calculated for gender and age groups, with the population aged $20+$ as the denominator. Mean numbers of consultations with standard deviation (SD) were calculated for each year. In addition, consultation was divided into three groups ('index date only', '1-2' or ' 3 or more' follow-up consultations), and rates with a $95 \%$ confidence interval (CI) were provided. Frequency of each type of GP depression care (talking therapy, long consultation, talking therapy and/or long consultation, referral to secondary care, sick leave certification among 20-66-year-olds) starting at index date, or after index date was calculated with a $95 \%$ CI. Rate and $95 \%$ CI of antidepressant drug treatment was established.

We defined a 'GP-consultation-population' comprising all GP consultations regardless of diagnosis, recorded in the KUHR database in the study period. We used this population to calculate the proportion of each type of treatment in consultations with a depression diagnosis and in consultations with other 
diagnoses, by year (panel a). For the study population, treatment rate and $95 \%$ CI of each type of treatment, by year of depression diagnosis, were presented as graphs by gender (panel b), age group (panel c), and comorbidity (panel d). Antidepressant use in the general population [29] and in patients with depression was presented as graphs (panel a). Antidepressant use in the study population was also presented for each of the covariates (panel b-d).

For each treatment type, a generalized linear model (GLM) was used to test for linear time trends. Further, the time trend for each value of the covariate was tested, and in addition, the interaction between year and the covariate was tested. To evaluate the significance of the test results, a level of $\alpha=0.001$ was applied. We provide the results of all tests by $p$-values in Supplementary Table 1. The data were analyzed using STATA/SE version 16.1 (Stata Statistical Software).

\section{Results}

The study comprised 365,947 new depression diagnoses in 307,237 unique patients. Mean patient age at index date was 44.3 years $(\mathrm{SD}=15.9$; men: $43.7(15.1)$; women:
44.6 (16.4)), and $61.9 \%$ were women. Most patients were of working age $(90.7 \%)$ and $41.3 \%$ had pre-existing comorbidity (27.0\% somatic, $9.3 \%$ mental, $5.0 \%$ both). The annual incidence of GP-recorded depression was $1.46 \%$ in 2009 and decreased slightly to $1.34 \%$ in 2015 . For the whole period, the incidence was $1.8 \%$ among women and $1.1 \%$ among men. Figure 1 provides ageand year-specific depression incidence for genders separately.

The mean number of GP consultations for depression was stable throughout the study period; this also applied for having an index consultation only, 1-2 follow-up consultation(s), and 3 or more follow-up consultations, respectively (Table 1).

The provision of talking therapy in a consultation increased during the study period (Fig. 2a). In terms of treatment rates for depression, talking therapy starting at index consultation increased from $27.0 \%$ to 2009 to $51.1 \%$ in 2015 , while talking therapy starting during follow-up was stable over the years (Table 1). Women had a larger increase in talking therapy provision compared to men (Fig. 2b). A larger
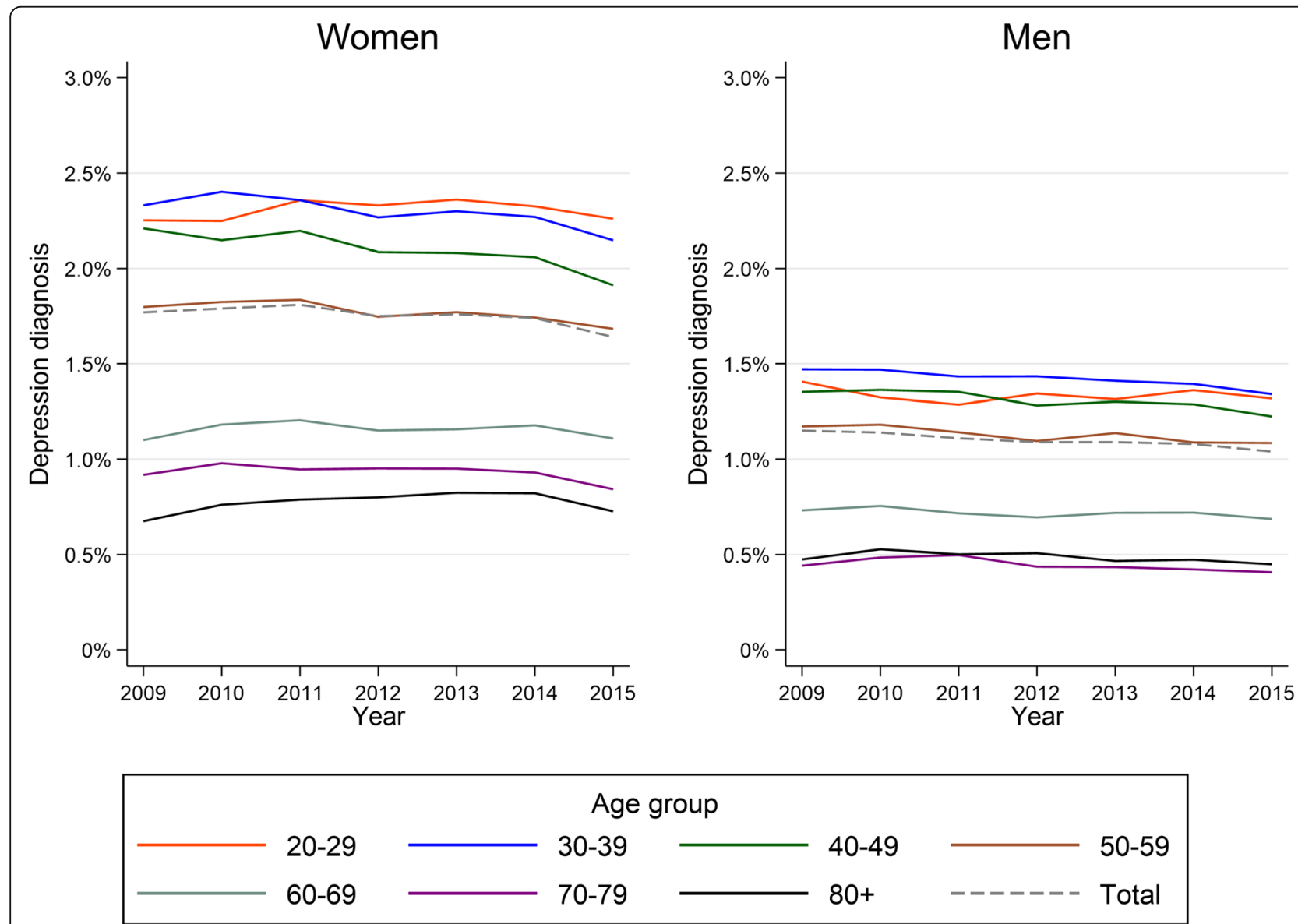

Fig. 1 Annual incidence of patients recorded with a new depression diagnosis in general practice, by gender and age group 


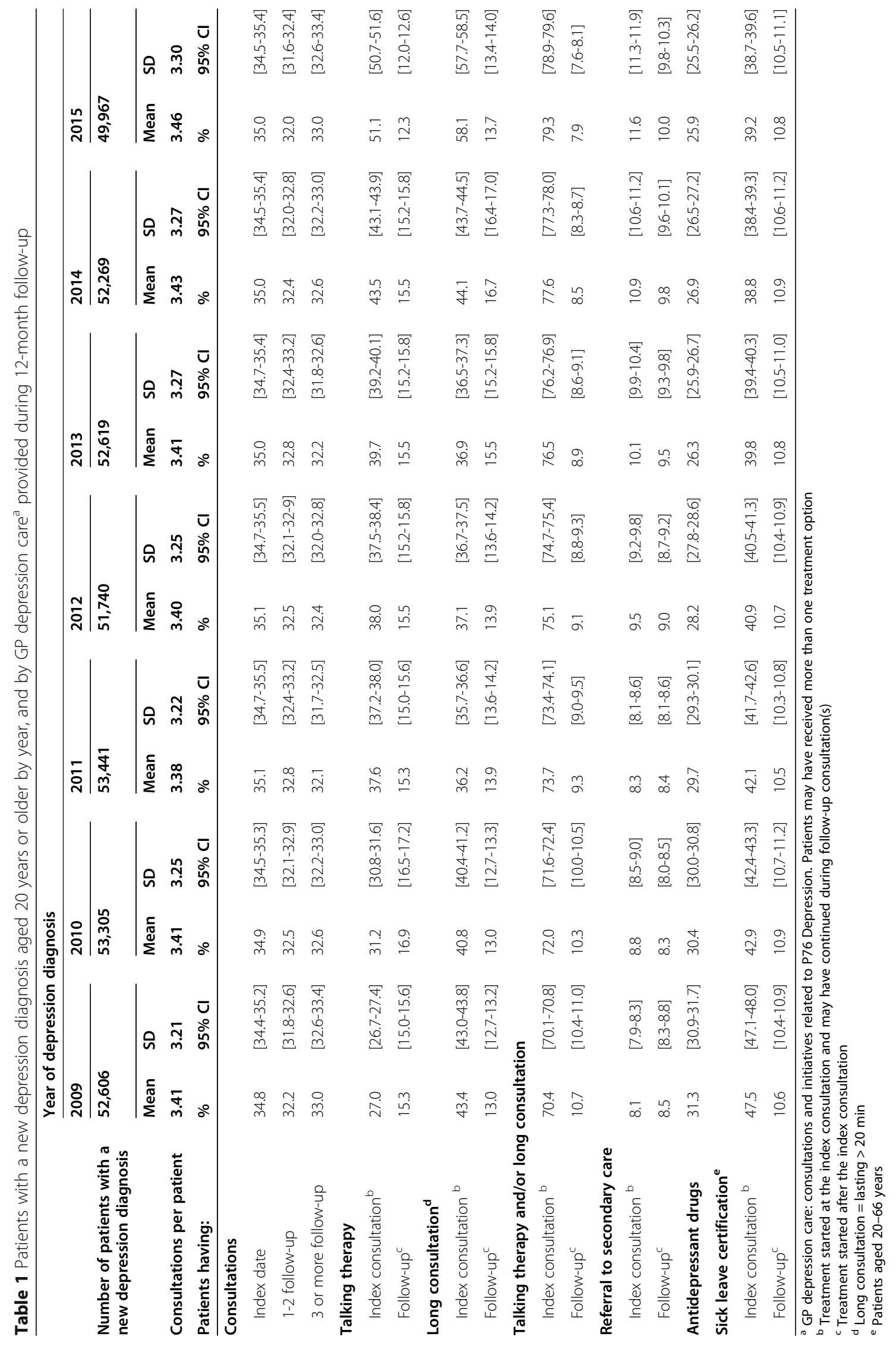



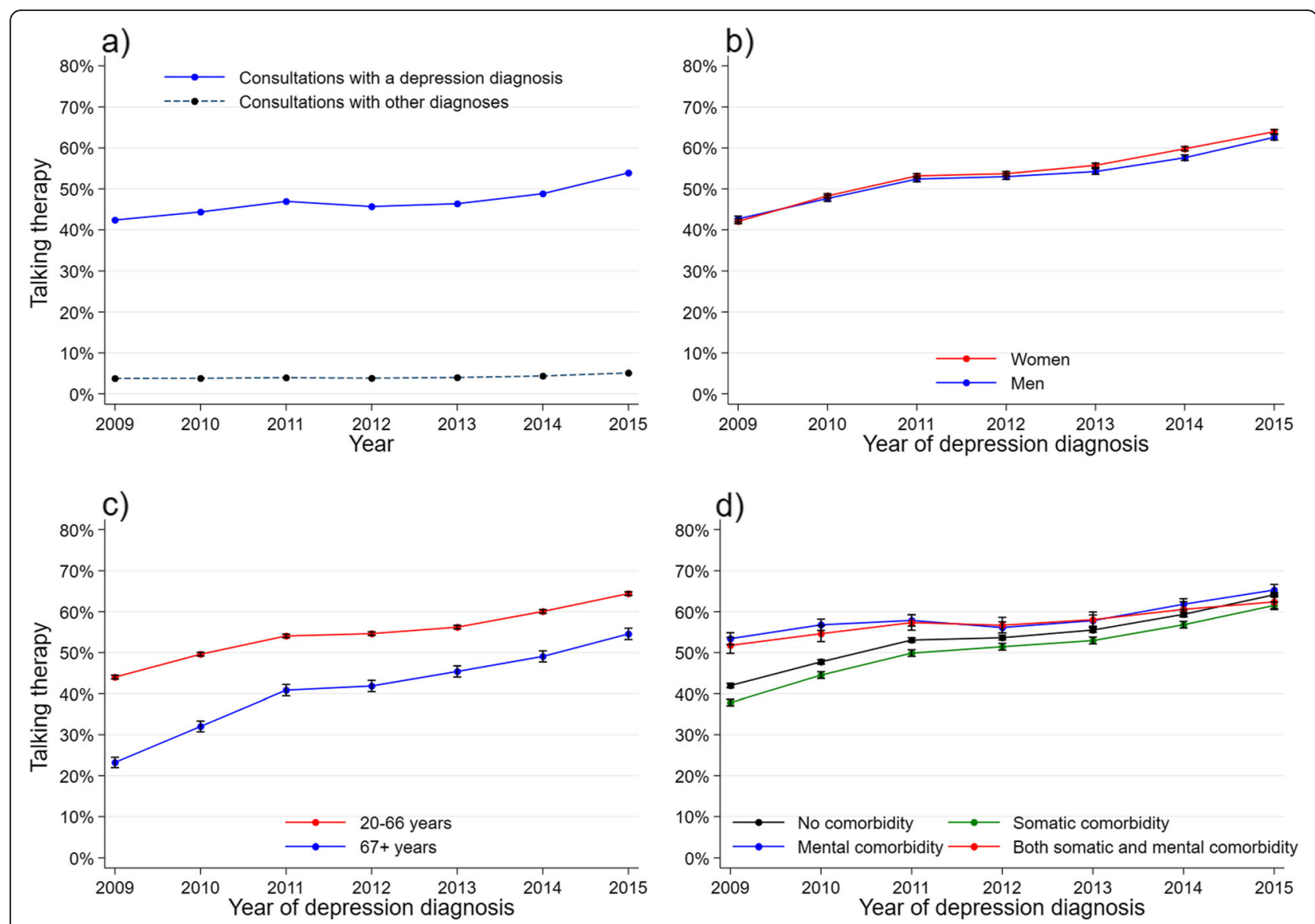

Fig. 2 Talking therapy by year. a GP population: proportion of talking therapy in consultations with a depression diagnosis, and consultations with other diagnoses. $\mathbf{b}$-d Study population: treatment rate and $95 \% \mathrm{Cl}$ during one-year follow up by $\mathbf{b}$ gender, $\mathbf{c}$ age group and $\mathbf{d}$ comorbidity

proportion of working-aged patients had talking therapy with the GP compared to patients aged 67+. However, the latter group had a greater increase in talking therapy during the first few years than the younger patients (Fig. 2c). Patients without comorbidity or with somatic comorbidity received less talking therapy early in the study period and gradually more in later years, reaching a similar level as those with comorbid mental conditions (Fig. 2d).

Long consultations (i.e., > $20 \mathrm{~min}$ ) increased during the study period, and the increase was pronounced from 2013 to 2015 for consultations with a depressed patient (Fig. 3a). For patients with a new depression diagnosis, the rates of long consultations starting at index consultation increased mainly in the last two years of the period, while long consultations starting during followup were stable (Table 1). The time trends for long consultations were similar for genders (Fig. 3b). Patients aged 67 thad higher rates of long consultations from 2009 to 2012, and from 2013, both age groups had increasing rates (Fig. 3c). Those with somatic comorbidity or without comorbidity had higher rates of long consultations compared to those with mental comorbidity, but differences became less pronounced towards the end of the study period (Fig. 3d).

The combination of talking therapy and/or long consultation starting at index consultation increased gradually over the years (Table 1).

There was a weak increase over the years to refer a patient to specialist mental health care in a consultation, both for depressed patients and patients with other diagnoses (Fig. 4a). For patients with depression, the referral rates at index date and during follow-up increased gradually (Table 1). Men, working-aged patients, and those without comorbidity were more commonly referred compared to women, those aged $67+$, and patients with comorbidity, respectively (Fig. 4b and d). However, there were no interactions between year and any of the covariates.

The proportion of depressed patients who were dispensed antidepressant drugs decreased from $31.3 \%$ to 2009 to $25.9 \%$ in 2015 (Table 1; Fig. 5a). Men had slightly higher treatment rates compared to women, but the time trends were similar for genders (Fig. 5b). For patients aged $67+$, the decrease in 


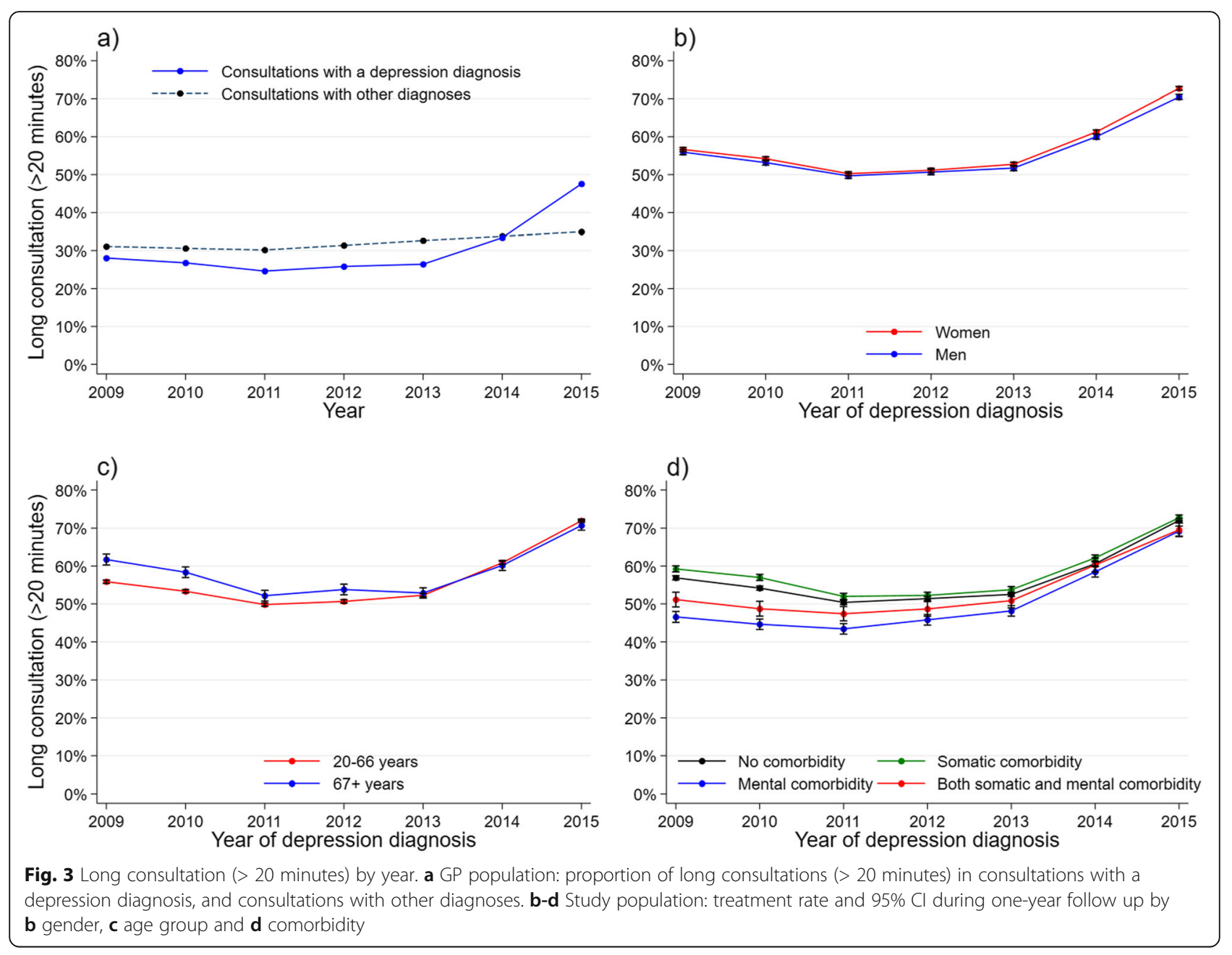

antidepressant use was more pronounced (from $52 \%$ to 2009 to $40 \%$ in 2015) than for working-aged patients (Fig. 5c). Drug treatment decreased among all categories of comorbidity, and the trends were similar (Fig. 5d).

Sick-listing by GP, regardless of diagnosis, decreased from 2009 to 2010 (Fig. 6a). For depressed patients, sick leave certified at index consultation decreased from $47.5 \%$ to 2009 to $39.2 \%$ in 2015 . About $10 \%$ of the patients were sick-listed during follow-up, and this percentage did not change throughout the period (Table 1). A greater share of women than men was sick-listed, and the decrease was more pronounced in men over the years (Fig. 6b). There was a reduction over time in sick leave certification for patients without comorbidity or with somatic comorbidity only. For those with mental comorbidity, sickness absence certification was lower than for other groups but did not change over time, and there was no interaction between year and comorbidity (Fig. 6c).

\section{Discussion}

\section{Summary}

In a nationwide cohort of patients with one or more new depression diagnoses, we examined time trends in depression care provided by the GP from 2009 to 2015. The one-year incidence rates of depression recorded in general practice decreased slightly during the study period. With respect to type of GP care, we found trends towards more provision of talking therapy, more long consultations, and more referral to secondary care, whereas drug treatment and sick-listing decreased over time. The time trends were different for gender (women had a greater increase in talking therapy and a smaller decrease in sick-listing, compared to men), age (working-aged patients had a smaller increase in talking therapy, a greater increase in long consultations, and a smaller decrease in antidepressant drug use, compared to older patients) and comorbidity (patients with mental comorbidity had a smaller increase in talking therapy and a greater increase in long consultations, compared to no comorbidity and somatic comorbidity). 


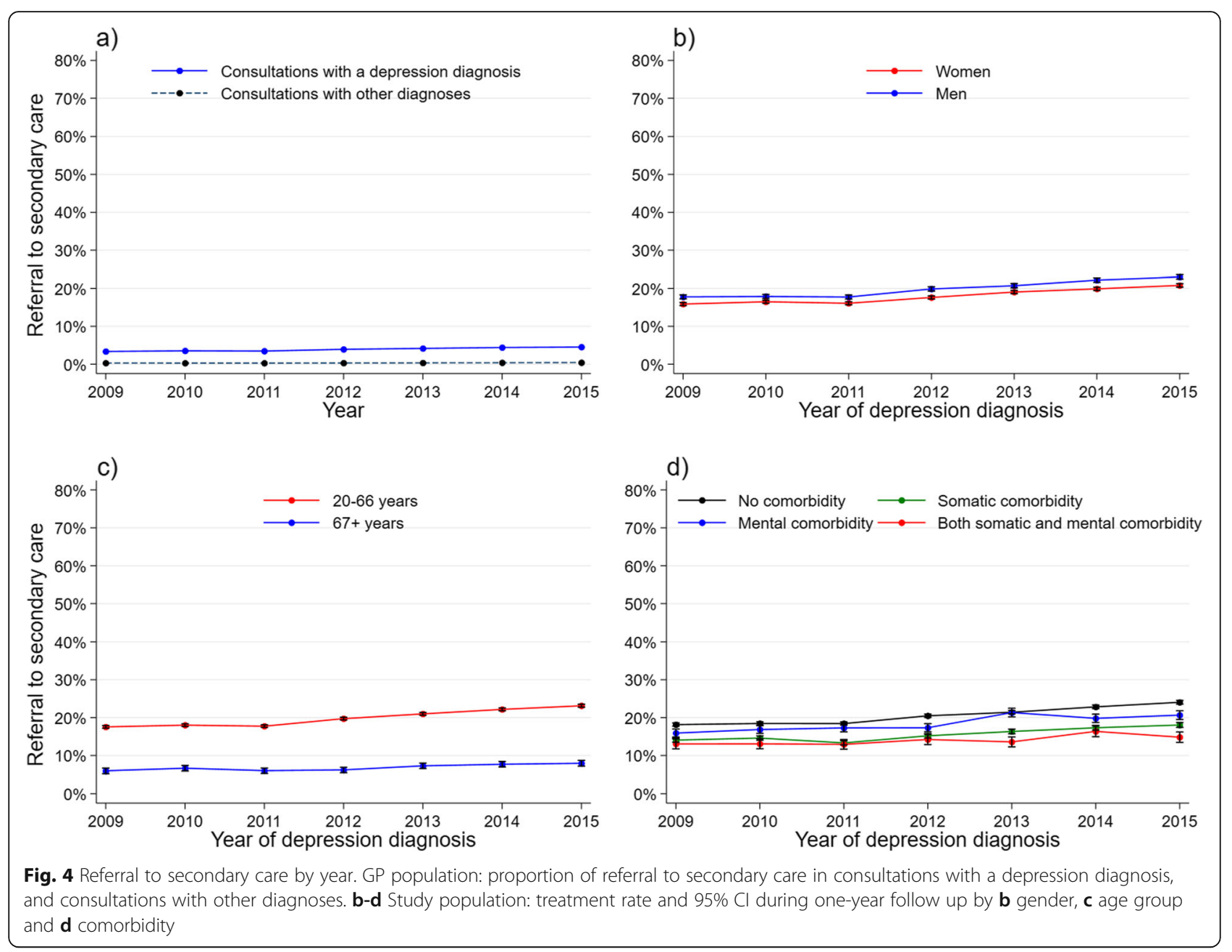

\section{Strengths and limitations}

The main strength of this study is the use of complete registry data from the publicly subsidized primary care services in Norway. Linked data from five national health- and population registries at the individual patient level provides a unique source of information, elimina-ting recall bias.

We defined a new depression diagnosis as a GPconsultation with the ICPC-2 code P76, after a one-year wash-out. However, our population was restricted to patients whose depression was identified by the GP and recorded as such. Patients with depression who did not seek help or were not diagnosed with depression by the GP remained beyond our scope. Further, information on the severity of depression was lacking, as ICPC-2 does not allow for such grading.

A limitation of using the reimbursement code for talking therapy was that the prerequisites were changed during the study period. The recorded reimbursement codes probably did not catch all performed GP talking therapy sessions, because referral to secondary mental care was a requirement until July 2011, and until July 2014, this code could not be combined with the higher rewarding reimbursement code for a long consultation (> $20 \mathrm{~min}$ ).

The NorPD contains complete data on all prescription drugs dispensed, thus we may have slightly underestimated the prevalence of prescribed antidepressants. To strengthen the internal validity, we have considered antidepressants reimbursed for the treatment of depression only. No information was available on the appropriateness of the different types of treatment provided.

The results of this study could be transferable to countries where GPs fulfill comparable roles to the Norwegian GPs (having fixed, personalized patient lists, and acting as gatekeepers), such as Sweden, the UK, and the Netherlands. They are less comparable with countries where GPs have different task assignments.

\section{Interpretation of findings and comparison with existing literature}

Patient population recorded with depression in general practice The gender distribution in our study population is consistent with previous research [30], reflecting a higher 


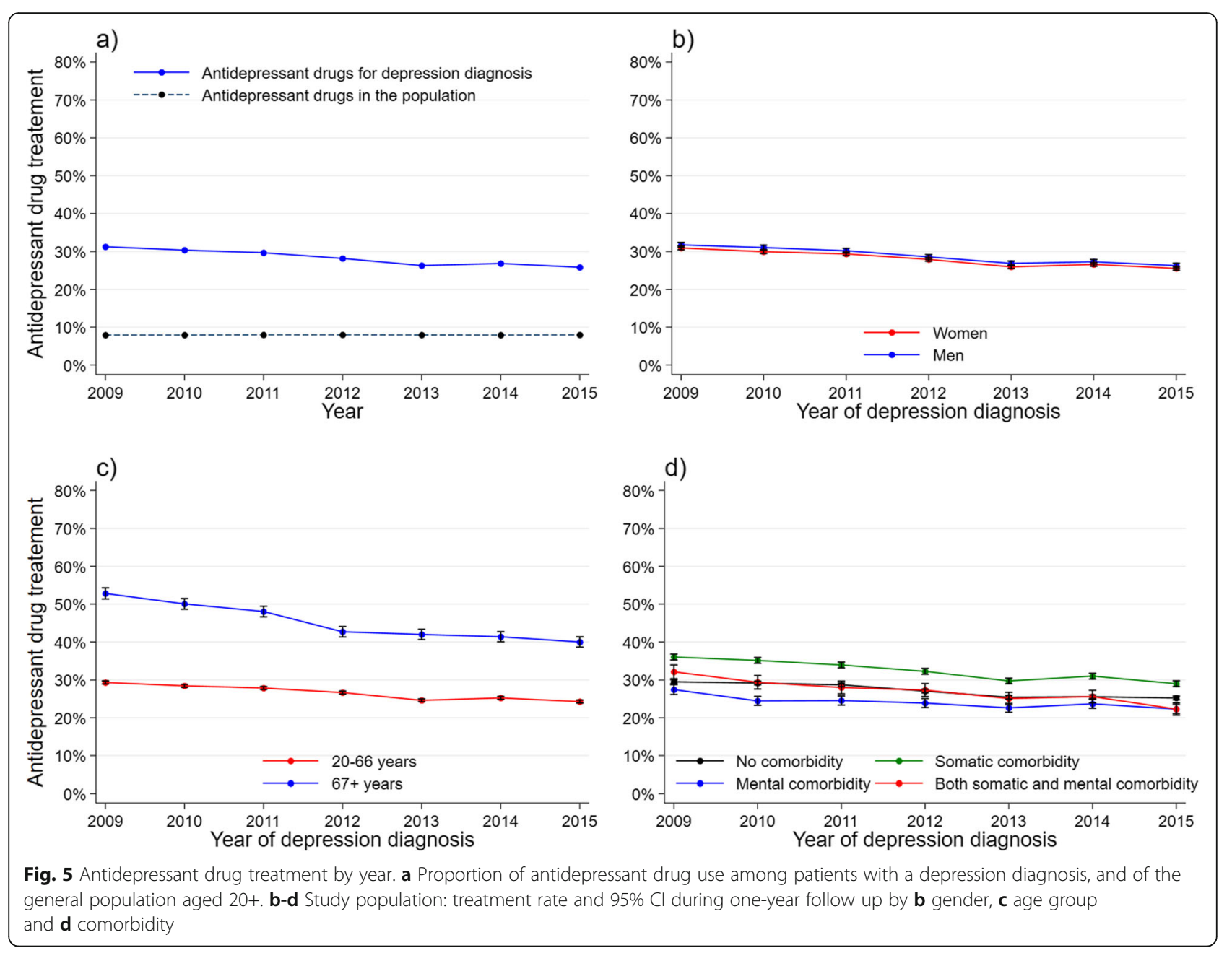

prevalence of depression [3] and more doctor-seeking [31] among women compared to men. Although older people are at greater risk of depression $[4,5]$, we found that the annual incidence of GP-recorded depression decreased with increasing age (Fig. 1). This may reflect that the course of depression becomes more prolonged / chronic with increasing age. Also, older people are less inclined to seek help for their psychological problems [32].

The decrease in annual incidence rate of GP-recorded depression is consistent with trends reported in the UK [33]. This change occurred in the context of increasing availability of low-threshold mental health services in the local communities and self-guided internet-based interventions. This raises the question whether people have changed their health care-seeking behavior, i.e., those with more severe depression seek their GP while those with less severe depression use the newly established low-threshold services instead. However, the Norwegian health registries do not include information at the individual level about the provision of lowthreshold services for depressed people. Further, the observed time trend to refer more patients, coinciding with increasing capacity in outpatient secondary mental care [13], was likely attributable to a selection of patients with more severe depression (in need of referral) and/or GPs' altered referral behavior.

\section{Time trends in GP-depression care}

Although there was a substantial increase in long consultations, the mean number of GP follow-up consultations did not change over time. In comparison, numbers of GP contacts for depression in the Netherlands increased after implementing a stepped collaborative depression programme [34] and integrating mental health nurses in primary care teams [35]. So far, however, such targeted initiatives have not been implemented in Norway.

Our findings indicate that provision of talking therapy increased, while antidepressant drug treatment decreased over time. These changes occurred following the publication of national guidelines that encourage improved targeting of drug treatment for depression and 


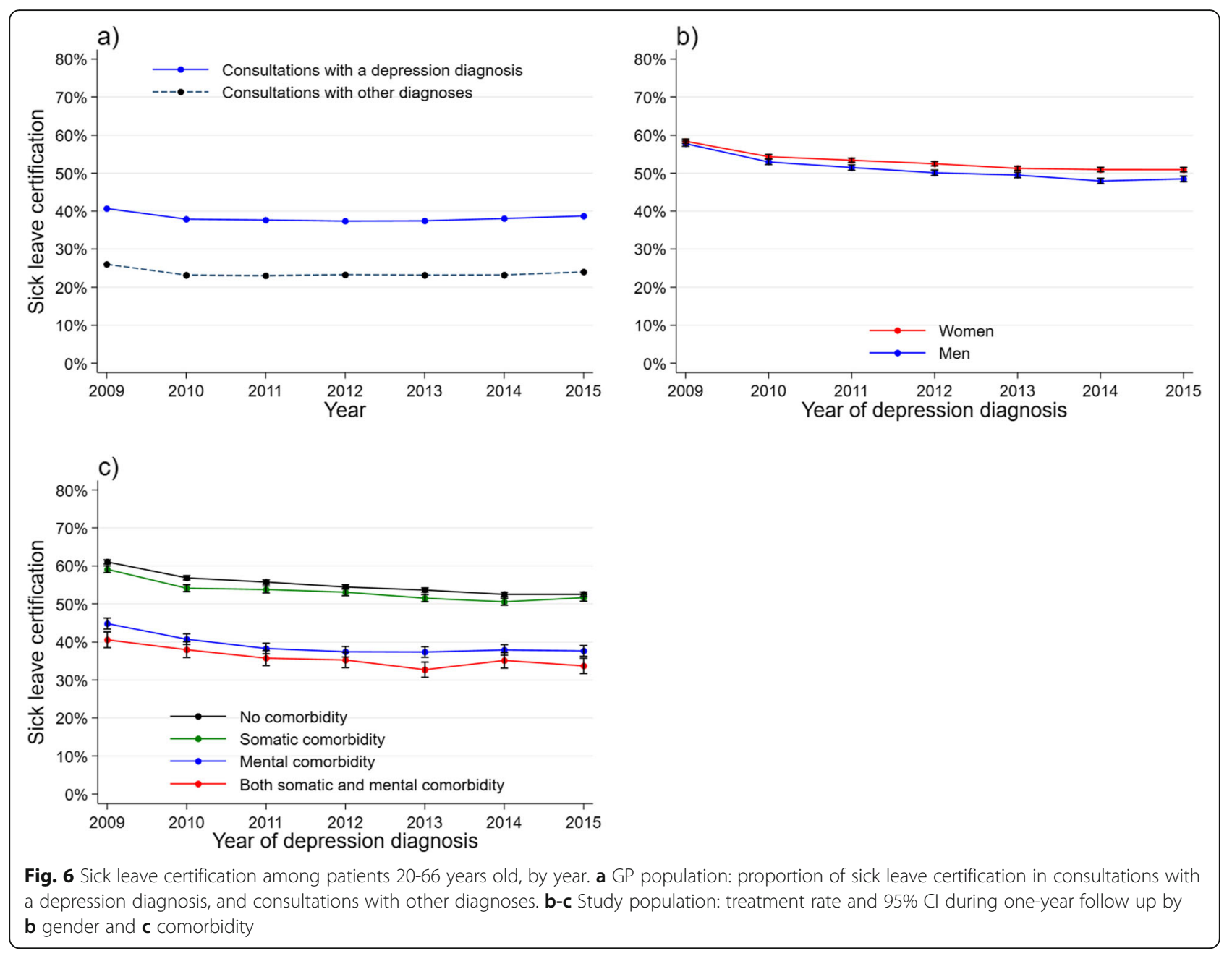

emphasize psychological treatment as GPs' primary tool in depression care [14]. Further, GPs' increasing provision of talking therapy and long consultations during the last years of the study was likely attributable (in part) to a change in the terms in mid-2014, i.e., both tariffs could be used together. Finally, patient preferences may be drivers of change as patients increasingly participate in the decision-making about their health care [36]. Notably, a meta-analytic review across different settings yielded a $70 \%$ greater patient preference for psychological treatment than for pharmacological treatment for depression [37].

From an international perspective, GPs' antidepressant prescribing rates in the Netherlands (2011-2015) decreased more than in Norway [21], while prescribing rates in the UK (2003-2013) declined only for first-ever depression episodes [22]. In US outpatient treatment of depression (2007-2015), the use of psychotherapy increased, while drug treatment remained stable [38]. Generally, the $26-31 \%$ antidepressant prescribing rates found in this study are considerably lower than the 45$75 \%$ rates reported in European countries with comparable primary care systems like the UK, the Netherlands, and Sweden $[21,22,30]$. This discrepancy may be due to the strict definitions of antidepressant drugs (excluding prescriptions issued for other diagnoses than depression) and drug dispensing data in this study.

The observed decrease over time in GPs' sick leave certification was attributable to less sick-listing starting at index date. This trend is in accordance with Norwegian government policy [18] and European policy [39], urging GPs to limit certification of sick leave in patients with mild mental disorders. Studies indicate that mental disorders have gradually replaced musculoskeletal problems as the main cause of sickness certification [40], with depression as the leading cause of GPs' sickness certification related to common mental disorders [41]. Possibly, intensified GP depression care in terms of more talking therapy and long consultation have contributed to reducing sickness absence [42]. 
Time trends related to patient gender, age, and comorbidity Men were slightly more likely to receive drug treatment and slightly less likely to be sick-listed, compared to women, consistent with previous research [29, 41, 43]. The greater proportion of women than men receiving talking therapy or long consultations with the GP, and the greater increase in talking therapy among women may be related to gendered patient preferences, i.e., women express and talk about their feelings more easily [44]. Greater referral rates and antidepressant prescription rates among men compared to women, may relate to less doctor-seeking [31], and more severe depression at diagnosis date.

The greater increase among older patients compared to working-aged patients has reduced but not eliminated the age gap regarding the provision of talking therapy. Also, referral rates for depressed patients aged 67 + were persistently lower than for working-aged patients, in line with findings in a comparable study in the UK [45]. An explanation of the observed age gap in psychological treatment in general practice and referral to secondary care may be that older people wish to solve their emotional problems autonomously and fear of stigma [46]. However, a systematic review of qualitative studies indicates that older people express preferences for talking therapies [47]. Further, the considerably higher antidepressant prescription rates for older patients than working-aged patients observed in this study are consistent with the beforementioned study in the UK [45]. Although the drug treatment rate for older patients decreased over time, it remained significantly higher than for patients of working age. This is of concern because antidepressants are associated with adverse events, such as falls and stroke, in older people [48].

The higher antidepressant treatment rate in patients with somatic comorbidity compared to those with mental comorbidity or without comorbidity was a surprising finding. Comparable studies of patients newly diagnosed with depression in general practice revealed higher prescription rates for Dutch patients with chronic somatic or psychiatric comorbidity [49], while prescription rates in the UK were lower for patients with comorbid so-matic illness [50], compared to those without comorbidity. Smolders et al. point out that GPs have higher contact rates with patients who suffer from multimorbidity and thus have more opportunities to treat their depression [49]. Further, our findings indicate that patients without comorbidity or with somatic comorbidity were more easily sick-listed than those with mental comorbidity. This difference may be attributable to patients with several mental conditions having more long-term periods of sick-leave, i.e., being not at risk of being sick-listed when a new depression episode starts. Also, GPs may have limited sick-listing of patients with mild mental disorders, in line with Norwegian [18] and European po-licy [39].

\section{Implications for research and/or practice}

The European Mental Health Action Plan 2013-2020 emphasized the importance of integrating mental health care into the general health care setting [9]. Worldwide, many initiatives have been undertaken to promote the substitution of mental health care from specialized care, e.g., provision of psychological treatment by the GP [27, 28]. Our findings support that most patients diag-nosed with depression by the GP are treated within general practice, in line with previous research [11]. The provision of talking therapy and long consultations increased substantially, in accordance with government policy in Norway. However, the average number of GP consultations for depression was unchanged. This may point at sustainability is being challenged because general practice as a service level has not been strengthened through the National Program for Mental Health [12] or other recent reforms.

\section{Conclusions}

The observed time trends in GP depression care towards more provision of psychological treatment, and less provision of pharmacological treatment and sick-leave certification were in the desired direction according to Norwegian health care policy. However, the large and persistent differences in treatment rates between working-aged and older patients is of concern. We have planned follow-up studies to examine the reasons for these differences. Further, clinical studies are needed to explore the implications of the observed changes for patient outcomes.

\section{Abbreviations \\ ATC: Anatomical Therapeutic Chemical; Cl: Confidence interval; \\ GLM: Generalized Linear Model; GP: General practitioner; ICD: International Classification of Disease; ICPC: International Classification of Primary Care; KUHR: Control and Reimbursement of Primary Health Care Claims Database; NorPD: Norwegian Prescription Database; NPR: Norwegian Patient Registry; WHO: World Health Organisation; YLD: Years lived with disability}

\section{Supplementary Information}

The online version contains supplementary material available at https://doi. org/10.1186/s12913-021-06712-w.

\section{Additional file 1.}

\section{Acknowledgements}

We thank Tatiana Fomina at Biostatistics and Data analysis core facility (BIOS) at the University of Bergen for help in facilitating data. We acknowledge Heidi Marie Meling for English language editing.

\section{Authors' contributions}

$S R, V B, I H, \varnothing H$, and TSS defined the research question, designed the study, and interpreted the results. SR and $\mathrm{IH}$ obtained approvals and acquired data. VB conducted the statistical analyses. SR and VB wrote the main manuscript text. VB prepared Table 1; Figs. 1, 2, 3, 4, 5 and 6. All authors reviewed the manuscript and approved the final version. 


\section{Funding}

Research Council of Norway (Grant number 287884).

\section{Availability of data and materials}

The data underlying this article were provided by the Norwegian Directorate of Health, the Norwegian Institute of Public Health, and Statistics Norway by permission. The data cannot be shared publicly due to restrictions by the Norwegian Data Protection Authority.

\section{Declarations}

\section{Ethics approval}

The study protocol has been approved by the Regional Committee for Medical and Health Research Ethics (REC) West (2017/934) and by the Norwegian Data Protection Authority (17/01372). This study used deidentified administrative health care data from national registries, and REC West granted an exemption from the consent requirement (2017/934). All methods were performed in accordance with the relevant guidelines and regulations.

\section{Consent for publication}

Not applicable.

\section{Competing interests}

The authors declare that they have no competing interests.

\section{Author details}

${ }^{1}$ Research Unit for General Practice, NORCE Norwegian Research Centre, Årstadveien 17, N-5009 Bergen, Norway. ${ }^{2}$ Department of Global Public Health and Primary Care, University of Bergen, Bergen, Norway. ${ }^{3}$ Division of Psychiatry, Haukeland University Hospital, Bergen, Norway.

\section{Received: 24 March 2021 Accepted: 30 June 2021}

Published online: 15 July 2021

\section{References}

1. GBD 2017 Disease and Injury Incidence and Prevalence Collaborators. Global, regional, and national incidence, prevalence, and years lived with disability for 354 diseases and injuries for 195 countries and territories, 1990-2017: a systematic analysis for the Global Burden of Disease Study 2017. Lancet. 2018;392:1789-1858.

2. Wittchen HU, Jacobi F, Rehm J, Gustavsson A, Svensson M, Jönsson B, et al. The size and burden of mental disorders and other disorders of the brain in Europe 2010. Eur Neuropsychopharmacol. 2011;21:655-79.

3. Ferrari AJ, Somerville AJ, Baxter AJ, Norman R, Patten SB, Vos T, et al. Global variation in the prevalence and incidence of major depressive disorder: a systematic review of the epidemiological literature. Psychol Med. 2013;43:471-81.

4. Alexopoulos GS. Depression in the elderly. Lancet. 2005;365:1961-70.

5. Rodda J, Walker Z, Carter J. Depression in older adults. BMJ. 2011;343:d5219.

6. Barnett K, Mercer SW, Norbury M, Watt G, Wyke S, Guthrie B. Epidemiology of multimorbidity and implications for health care, research, and medical education: a cross-sectional study. Lancet. 2012;380:37-43.

7. Read JR, Sharpe L, Modini M, Dear BF. Multimorbidity and depression: A systematic review and meta-analysis. J Affect Disord. 2017;221:36-46.

8. Wittchen HU, Jacobi F. Size and burden of mental disorders in Europe - a critical review and appraisal of 27 studies. Eur Neuropsychopharmacol. 2005;15:357-76.

9. World Health Organisation (WHO). The European Mental Health Action Plan 2013-2020. https://www.euro.who.int/_data/assets/pdf_file/0020/280604/ WHO-Europe-Mental-Health-Acion-Plan-2013-2020.pdf Accessed 23 Mar 2021.

10. Verhaak PF, van Dijk CE, Nuijen J, Verheij RA, Schellevis FG. Mental health care as delivered by Dutch general practitioners between 2004 and 2008. Scand J Prim Health Care. 2012;30:156-62.

11. Wang PS, Aguilar-Gaxiola S, Alonso J, Angermeyer MC, Borges G, Bromet EJ, et al. Use of mental health services for anxiety, mood, and substance disorders in 17 countries in the WHO world mental health surveys. Lancet. 2007:370:841-50.

12. Ministry of Health and Care Services. Opptrappingsplanen for psykisk helse (1999-2008). St.prp. nr. 63 (1997-98). [National Program for Mental Health]. https://www.regjeringen.no/no/dokumenter/stprp-nr-63-1997-98-/id201915/ Accessed 23 Mar 2021.
13. The Norwegian Research Council. Evaluering av Opptrappingsplanen for psykisk helse (2001-2009). [Evaluation of the National Program for Mental Health (2001-2009)]. ISBN 978-82-12-02678-0. Oslo, 2009

14. Norwegian Board of Health. Nasjonale retningslinjer for diagnostisering og behandling av voksne med depresjon (IS-1561). Oslo: National guidelines for diagnosis and treatment of adults with depression; 2009.

15. Brugha TS, Bebbington PE, Singleton N, Melzer D, Jenkins R, Lewis G, et al. Trends in service use and treatment for mental disorders in adults throughout Great Britain. Br J Psychiatry. 2004;185:378-84.

16. Mojtabai R. Increase in antidepressant medication in the US adult population between 1990 and 2003. Psychother Psychosom. 2008;77:83-92.

17. National Institute for Health and Clinical Excellence (NICE), 2009. Depression in adults: recognition and management. Clinical Guideline CG90. https:// www.nice.org.uk/guidance/cg90/resources/depression-in-adultsrecognition-and-management-pdf-975742636741 Accessed 23 Mar 2021.

18. The Norwegian Directorate of Health. Sykmelderveileder. [Norwegian guideline for sickness absence certification] https://www.helsedirektoratet. no/veiledere/sykmelderveileder Accessed 23 Mar 2021.

19. Ramanuj P, Ferenchick EK, Pincus HA. Depression in primary care: part 2 management. BMJ. 2019;365:1835.

20. Macdonald S, Maxwell M, Wilson P, Smith M, Whittaker W, Sutton M, et al. A powerful intervention: general practitioners' use of sickness certification in depression. BMC Fam Pract. 2012;13:82.

21. Magnée T, de Beurs DP, Schellevis FG, Verhaak PF. Antidepressant prescriptions and mental health nurses: an observational study in Dutch general practice from 2011 to 2015. Scand J Prim Health Care. 2018;36:47-55.

22. Kendrick T, Stuart B, Newell C, Geraghty AW, Moore M. Did NICE guidelines and the Quality Outcomes Framework change GP antidepressant prescribing in England? Observational study with time trend analyses 2003 2013. J Affect Disord. 2015;186:171-7.

23. The Norwegian Ministry of Health and Care Services. The introduction of a regular general practitionaer scheme. Oslo, 2001. https://www.regjeringen. no/en/dokumenter/regulation-relating-to-a-municipal-regul/id420530/ Accessed 18 Feb 2021.

24. Lindahl AK, Ringard A. The Norwegian Health System 2013. In: International profiles of health care systems (pp.104-112). Edition: Report no. 1717. Publisher: The Commonwealth Fund. Ed: Thompson S, Osborn R, Squires D, Jun M.

25. Nielen MMJ, Spronk I, Davids R, Korevaar JC, Poos R, Hoeymans N, Opstelten W, van der Sande MAB, Biermans MCJ, Schellevis FG, Verheij RA. Estimating morbidity rates based on routine electronic health records in primary care: observational study. JMIR Med Inform. 2019;26(3):e11929.

26. NHS Health Scotland. Talking Therapies Explained. 2018. https://www. nhsinform.scot/healthy-living/mental-wellbeing/therapy-and-counselling/ta Iking-therapies-explained Accessed 18 Feb 2021.

27. Bower $P$, Knowles $S$, Coventry PA, Rowland A. Counselling for mental health and psychosocial problems in primary care. Cochrane Database Syst Rev. 2011;9:CD001025.

28. Cape J, Whittington C, Buszewicz M, Wallace P, Underwood L. Brief psychological therapies for anxiety and depression in primary care: metaanalysis and meta-regression. BMC Med. 2010;8:38.

29. Norwegian Institute of Public Health. The statistical database for prescription drug dispensing: https://www.fhi.no/en/hn/health-registries/norpd/ Accessed 23 Mar 2021

30. Lytsy P, Hallqvist J, Alexanderson K, Åns A. Gender differences in healthcare management of depression: aspects of sick leave and treatment with psychoactive drugs in a Swedish setting. Nord J Psychiatry. 2019;73:441-50.

31. Wang Y, Hunt K, Nazareth I, Freemantle N, Petersen I. Do men consult less than women? An analysis of routinely collected UK general practice data. BMJ Open. 2013;3:e003320

32. Dorow M, Löbner M, Pabst A, Stein J, Riedel-Heller SG. Preferences for depression treatment including internet-based Interventions: Results from a large sample of primary care patients. Front Psychiatry. 2018;9:181.

33. Kendrick T, Stuart B, Newell C, Geraghty AW, Moore M. Changes in rates of recorded depression in English primary care 2003-2013: Time trend analyses of effects of the economic recession, and the GP contract quality outcomes framework (QOF). J Affect Disord. 2015;180:68-78.

34. Gidding LG, Spigt MG, Dinant GJ. Stepped collaborative depression care: primary care results before and after implementation of a stepped collaborative depression programme. Fam Pract. 2014;31:180-92. 
35. Magnée T, de Beurs DP, de Bakker DH, Verhaak PF. Consultations in general practices with and without mental health nurses: an observational study from 2010 to 2014. BMJ Open. 2016;6:e011579.

36. Hopwood M. The shared decision-making process in the pharmacological management of depression. Patient. 2020;13:23-30.

37. McHugh RK, Whitton SW, Peckham AD, Welge JA, Otto MW. Patient preference for psychological vs pharmacologic treatment of psychiatric disorders: a meta-analytic review. J Clin Psychiatry. 2013;74:595-602.

38. Hockenberry JM, Joski P, Yarbrough C, Druss BG. Trends in treatment and spending for patients receiving outpatient treatment of depression in the United States, 1998-2015. JAMA Psychiatry. 2019;76:810-7.

39. OECD. Mental Health and Work. Fit mind, fit job: From evidence to practice in mental health and work. Paris, France: OECD Publishing; 2015.

40. Harvey SB, Joyce S, Modini M, Christensen H, Bryant R, Mykletun A, et al. Work and depression/ anxiety disorders - a systematic review of reviews: final report. Melbourne, Australia: Beyondblue; 2013.

41. Gjesdal S, Holmaas TH, Monstad K, Hetlevik Ø. GP consultations for common mental disorders and subsequent sickness certification: registerbased study of the employed population in Norway. Fam Pract. 2016;33:656-62.

42. Rost $\mathrm{K}$, Smith JL, Dickinson M. The effect of improving primary care depression management on employee absenteeism and productivity. A randomized trial. Med Care. 2004;42:1202-10.

43. Mallen CD, Wynne-Jones G, Dunn KM. Sickness certification for mental health problems: an analysis of a general practice consultation database. Prim Health Care Res Dev. 2011:12:179-82

44. Houle J, Villaggi B, Beaulieu MD, Lespérance F, Rondeau G, Lambert J. Treatment preferences in patients with first episode depression. J Affect Disord. 2013;147:94-100

45. Walters K, Falcaro M, Freemantle N, King M, Ben-Shlomo Y. Sociodemographic inequalities in the management of depression in adults aged 55 and over: an analysis of English primary care data. Psychol Med. 2018:48:1504-13.

46. Kitchen KA, McKibbin CL, Wykes TL, Lee AA, Carrico CP, McConnell KA. Depression treatment among rural older adults: Preferences and factors influencing future service use. Clin Gerontol. 2013;36:10.

47. Frost R, Beattie A, Bhanu C, Walters K, Ben-Shlomo Y. Management of depression and referral of older people to psychological therapies: a systematic review of qualitative studies. Br J Gen Pract. 2019:69:e171-e181.

48. Coupland C, Dhiman P, Morriss R, Arthur A, Barton G, Hippisley-Cox J. Antidepressant use and risk of adverse outcomes in older people: population based cohort study. BMJ. 2011;343:d4551.

49. Smolders M, Laurant M, van Rijswijk E, Mulder J, Braspenning J, Verhaak $P$, et al. Depressed and a co-morbid condition: more psychotropics prescribed! Eur J Gen Pract. 2008;14:10-8

50. Kendrick T, Dowrick C, McBride A, Howe A, Clarke P, Maisey S, et al. Management of depression in UK general practice in relation to scores on depression severity questionnaires: analysis of medical record data. BMJ. 2009;338:b750.

\section{Publisher's Note}

Springer Nature remains neutral with regard to jurisdictional claims in published maps and institutional affiliations.

Ready to submit your research? Choose BMC and benefit from:

- fast, convenient online submission

- thorough peer review by experienced researchers in your field

- rapid publication on acceptance

- support for research data, including large and complex data types

- gold Open Access which fosters wider collaboration and increased citations

- maximum visibility for your research: over $100 \mathrm{M}$ website views per year

At BMC, research is always in progress.

Learn more biomedcentral.com/submissions 